\title{
TEKNOLOGI VRML UNTUK MEDIA PROMOSI MOBIL BERBASIS WEB
}

Aditya Nur Prasetyo ${ }^{1)}$, Kodrat Iman Satoto ${ }^{2)}$, Kurniawan Teguh Martono ${ }^{2)}$

Program Studi Sistem Komputer, Fakultas Teknik, Universitas Diponegoro

Jln. Prof. Sudharto, Tembalang, Semarang, Indonesia

Email: aditya_prasetyo022@yahoo.co.id

\begin{abstract}
Abstrak - Peranan teknologi informasi menjadi hal utama yang harus dipenuhi untuk menunjang kegiatan dalam berbagai bidang kehidupan, tidak terkecuali bidang promosi suatu produk atau jasa. Dengan penggunaan internet penyampaian informasi mengenai produk yang dipromosikan menjadi lebih mudah dan dapat diakses setiap saat dan dapat dilakukan dimana saja. Medianya pun juga telah berkembang dengan berbagai macam kemudahan, salah satunya adalah media promosi berbasis multimedia. Teknologi virtual reality merupakan salah satu teknologi yang berbasis multimedia dengan memadukan berbagai elemen multimedia. Dengan penggunaan teknologi virtual reality tersebut diharapkan dapat menunjang media promosi agar lebih interaktif, efektif dan menarik.
\end{abstract}

Aplikasi yang dikembangkan merupakan perpaduan antara teknologi virtual reality dengan website. Teknologi virtual reality akan menyajikan produk mobil yang dipromosikan melalui tampilan tiga dimensi yang interaktif. Teknologi tersebut kemudian ditanamkan dalam website sehingga memungkinkan pengguna dapat mengaksesnya kapan dan dimana saja. Teknologi virtual reality dikembangkan menggunakan VRML (Virtual Reality Modelling Language) dan software pemodelan $3 D$ 3ds Max, sedangkan aplikasi berbasis web dikembangkan menggunakan bahasa pemrograman PHP, HTML dan CSS. Aplikasi tersebut juga didukung penggunaan basis data MySQL sehingga mempermudah user dalam mengolah data. Browser yang digunakan perlu dipasangi plug-in Cortona3D Viewer agar dapat menampilkan file tiga dimensi.

Hasil dari pembuatan aplikasi ini adalah terancangnya sebuah aplikasi yang menggunakan teknologi VRML untuk media promosi mobil berbasis web. Hasil pengujian menunjukkan bahwa aplikasi ini menjalankan fungsionalitasnya sesuai dengan rancangan.

Kata Kunci : Media Promosi, Virtual Reality, VRML, Website, PHP, HTML, CSS, MySQL, Cortona3D Viewer

\section{PENDAHULUAN}

1.1 Latar Belakang

Perkembangan teknologi semakin pesat pada masa kini. Kemajuan ini membuat teknologi informasi menjadi kebutuhan yang tidak bisa dihiraukan lagi. Peranan teknologi menjadi hal utama yang harus dipenuhi untuk menunjang kegiatan dalam berbagai bidang kehidupan. Tuntutan masyarakat yang menginginkan sesuatu yang praktis membuat internet menjadi hal yang harus ada. Dengan adanya internet pertukaran informasi menjadi lebih mudah dan dapat di akses setiap saat dan dapat dilakukan dimana saja. Media online dewasa ini semakin berkembang dengan berbagai macam kemudahan, misalnya teknologi 3 dimensi (3D) yang menggambarkan suatu bentuk nyata berada di dunia virtual, teknologi tersebut mampu memberikan visualisasi mengenai informasi yang ingin disampaikan. Teknologi 3D tersebut dapat dikombinasikan dengan website menggunakan Virtual Reality Modelling Language (VRML) sehingga dapat diakses dimanapun dan kapanpun. VRML adalah teknologi untuk membuat model objek 3D sekaligus aksi yang akan diterapkan pada objek 3D tersebut. Oleh sebab itu, VRML dapat digunakan sebagai media presentasi visual yang praktis dan detail.

Media promosi mobil saat ini sudah banyak menggunakan media online sehingga konsumen dapat mengaksesnya dimanapun dan kapanpun. Namun, dari segi tampilannya promosi mobil masih banyak menggunakan tampilan 2 dimensi (2D). Tampilan 2D hanya dapat memberikan gambaran informasi dalam satu muka (sisi) saja, sehingga untuk melihat suatu objek mobil secara utuh yang dapat dilihat dari segala sisi diperlukan banyak gambar 2D untuk menampilkannya. Kelemahan tampilan 2D tersebut dapat diatasi dengan menerapkan teknologi 3D. Teknologi 3D dapat menggambarkan suatu bentuk nyata berada di dunia virtual, sehingga dapat menggambarkan bentuk mobil secara utuh yang dapat dilihat dari segala sisi.

Pada tugas akhir ini akan mengembangkan website promosi mobil berbasis 3D dengan menggunakan teknologi VRML. Diharapkan dengan penggunaan teknologi VRML ini akan membantu dalam menampilkan produk mobil dalam tampilan 3D yang interaktif yang dapat dilihat dari segala sisi. Dengan menerapkan teknologi 3D tersebut dalam website, maka diharapkan konsumen dapat mengaksesnya dimana pun dan kapan pun.

\subsection{Rumusan Masalah}

1. Bagaimana membuat aplikasi yang interaktif untuk dimanfaatkan sebagai media promosi mobil?

2. Bagaimana mendesain objek mobil 3D menggunakan VRML untuk digunakan sebagai media promosi mobil yang interaktif?

3. Bagaimana merancang aplikasi berbasis web yang mendukung teknologi VRML?

\subsection{Batasan Masalah}

Penulisan tugas akhir ini pembahasan masalah memiliki batasan dalam hal berikut:

1. Objek mobil 3D dikembangkan menggunakan teknologi VRML (Virtual Reality Modelling Language) dengan menggunakan software 3D Studio Max 2010 dan VrmlPad.

2. Aplikasi yang dikembangkan merupakan aplikasi berbasis web dengan plug-in Cortona3D pada browser. 
3. Aplikasi berbasis web dibangun menggunakan bahasa pemrograman PHP, HTML, CSS, Javascript, dan JQuery serta menggunakan database MySQL.

4. Pengujian sistem dilakukan pada browser Google Chrome, Mozilla Firefox dan Internet Explorer.

1.4 Tujuan

1. Merancang aplikasi interaktif berbasis web sebagai media promosi mobil.

2. Mengimplementasikan teknologi VRML untuk mendukung aplikasi interaktif berbasis web sebagai media promosi mobil.

\section{DASAR TEORI}

\subsection{HTML}

HTML (Hyper Text Markup Language) merupakan file teks murni yang dapat di buat menggunakan berbagai editor teks. Dokumen ini dikenal sebagai web page. Dokumen HTML merupakan dokumen yang disajikan dalam browser web surfer. Dokumen ini umumnya berisi informasi atau interface aplikasi di dalam internet.

HTML tersusun oleh elemen-elemen. "Elemen" merupakan istilah bagi komponen-komponen dasar pembentuk dokumen HTML. Beberapa contoh dari elemen adalah head, body, table, paragraph, dan list. Tag digunakan utnuk menandai berbagai elemen dalam suatu dokumen HTML. Tag HTML terdiri atas sebuah kurung sudut kiri ( $<$, tanda lebih kecil) dan ditutup dengan kurung sudut kanan (>, tanda lebih besar). Tag pada umumnya berpasangan dan pasangannya diawali dengan garis miring. Tag yang pertama menunjukkan awal elemen dan tag kedua menunjukkan akhir elemen (Hirin \& Virgi 2011).

\subsection{PHP}

PHP adalah salah satu bahasa pemrograman skrip yang dirancang untuk membangun aplikasi web. Ketika dipanggil dari web browser, program yang ditulis dengan PHP akan di-parsing didalam web server oleh interpreter PHP dan diterjemahkan ke dalam dokumen HTML, yang selanjutnya akan ditampilkan kembali ke web browser. Karena pemrosesan program PHP dilakukan di lingkungan web server, PHP dikatakan sebagai bahasa sisi server (server-side). Oleh sebab itu, kode PHP tidak akan terlihat pada saat user memilih perintah "View Source" pada web browser yang mereka gunakan (Raharjo et al. 2012).

PHP adalah salah satu bahasa pemrograman yang berjalan dalam sebuah webserver dan berfungsi sebagai pengolah data pada sebuah server. Untuk membuat website yang dinamis dan mudah untuk diupdate setiap saat dari browser, dibutuhkan sebuah program yang mampu mengolah data dari komputer client atau komputer server itu sendiri sehingga mudah dan nyaman untuk disajikan di browser. Dengan menggunakan program PHP, sebuah website akan lebih interaktif dan dinamis (Madcoms 2011).

\subsection{CSS}

CSS yang merupakan singkatan dari Cascading Style Sheets, merupakan bahasa pemrograman yang digunakan untuk menggambarkan semantik presentasi (tampilan dan format) dari dokumen yang dituliskan dengan menggunakan markup language. CSS digunakan untuk memberikan gaya tampilan pada sebuah halaman web yang dituliskan dengan menggunakan bahasa HTML atau xHTML, tetapi bahasa ini juga bisa diaplikasikan pada setiap jenis dokumen XML.

CSS didesain untuk memisahkan konten dokumen dengan presentasi dokumen, termasuk elemen seperti layout, warna, dan pilihan huruf (font). Pemisahan ini akan memberikan keuntungan dalam hal aksesibilitas konten, meningkatkan fleksibilitas, dan memungkinkan beberapa halaman untuk berbagi format yang sama serta mampu mengurangi kompleksitas dan pengulangan dalam penulisan atau struktur konten (Hirin \& Virgi 2011).

\subsection{Javascript}

Javascript adalah bahasa yang berbentuk kumpulan skrip yang pada fungsinya berjalan pada suatu dokumen HTML, sepanjang sejarah internet bahasa ini adalah bahasa skrip pertama untuk web. Bahasa ini adalah bahasa pemrograman untuk memberikan kemampuan tambahan terhadap bahasa HTML dengan mengijinkan pengeksekusian perintah perintah di sisi user, yang artinya di sisi browser bukan di sisi server web (Wahyono 2009).

\subsection{JQuery}

JQuery merupakan sebuah Javascripts Library atau bisa disebut juga sebagai perpustakaan dari kumpulan kode/listing Javascript yang siap pakai. Dalam arti sederhana, JQuery dapat digunakan untuk meringkas sebuah listing Javascript yang panjang dalam sebuah proyek pembuatan website. Sehingga sebagai web developer, akan diberikan kremudahan dalam menghadapi bagian yang mengandung Javascript. JQuery merupakan program yang berjalan pada sisi server dan akan ditampilkan pada web browser. JQuery dapat berjalan di dalam HTML, atau pemrograman berbasis web lainnya seperti PHP atau JSP (Adi \& Sanjaya 2012).

\subsection{MySQL}

MySQL merupakan basisdata yang menggunakan konsep RDBMS, sebuah tabel merupakan struktur penyimpanan dasar. Satu tabel atau lebih membentuk sebuah relational database.

MySQL adalah Relational Database Management System (RDBMS) yang didistribusikan secara gratis di bawah lisensi GPL (General Public Licence). Dimana setiap orang bebas untuk menggunakan $M y S Q L$, namun tidak boleh dijadikan 
produk turunan yang bersifat closed source atau komersial (Madcoms 2004).

\section{$2.7 \quad$ Virtual Reality}

Virtual Reality didefinisikan sebagai simulasi objek 3D (tiga-dimensi) dengan menggunakan komputer yang dapat dinavigasikan atau dikontrol secara interaktif oleh user (pengguna) di dalam lingkungan dunia maya. Dunia maya tiga dimensi atau virtual reality (VR) merupakan teknologi visualisasi untuk menirukan alam nyata ke dalam dunia maya (Anwar 1999a).

Secara sederhana, virtual reality adalah pemunculan gambar-gambar atau model tiga dimensi yang dibangkitkan computer, yang terlihat nyata dengan bantuan sejumlah peralatan tertentu (Paoluzzi 2003).

\subsection{VRML}

VRML (Virtual Reality Modelling Language) adalah sebuah bahasa pemrograman yang diciptakan khusus untuk membuat objek-objek 3D. Objek-objek yang dibuat dengan VRML akan memiliki tiga buah dimensi panjang, lebar dan kedalaman, sehingga dapat dipandang dari setiap sudut (Kurniadi 1999). Bahasa ini memberikan berbagai kemudahan bagi pengguna untuk melakukan visualisasi objek-objek 3D (Anwar 1999b). VRML menggambarkan objek 3D yang dapat dikendalikan secara interaktif oleh pengguna dan dapat ditampilkan pada web (Anwar 1999a).

\subsection{VRML Browser}

VRML browser membaca file yang berisi kodekode VRML dan kemudian menerjemahkannya menjadi gambar grafis 3D (Paoluzzi 2003).

Ada dua jenis VRML browser, yaitu VRML browser versi plug-in dan stand-alone. Dinamakan VRML plug-in browser karena software ini digunakan bersama-sama dengan software lain yaitu peramban web atau HTML browser. Contoh software penampil 3D yaitu Cortona3D Viewer. Tanpa HTML browser VRML plug-in ini tidak dapat dipakai untuk membaca dan menampilkan isi file VRML. Sebaliknya, standalone VRML browser dapat digunakan tanpa ketergantungan pada software lain (Anwar 1999a).

\subsection{Cortona3D Viewer}

Cortona3D adalah penampil 3D yang cepat dan sangat interaktif. Satu set renderer 3D yang dioptimalkan untuk menjamin kualitas visual terbaik pada PC dengan video card terbaru dan juga PC dengan kemampuan video card dasar.

Cortona3D Viewer (sebelumnya dikenal sebagai Client VRML Cortona) bekerja sebagai VRML plugin untuk browser internet yang populer (Internet Explorer, Mozilla Firefox, Google Chrome, Opera dll) dan aplikasi office (Microsoft PowerPoint, Microsoft Word, dll). Pada saat ini Cortona3D Viewer tersedia pada platform Windows. Cortona3D lebih dari sekedar viewer atau penampil 3D. API yang kuat memungkinkan untuk integrasi Cortona ke semua aplikasi pihak ketiga yang mendukung teknologi ActiveX. Dengan Cortona3D, Anda dapat membuat berbagai macam aplikasi 3D (dapat memungkinkan untuk dikembangkan 3D untuk layanan online).

\subsection{VrmlPad}

VrmlPad merupakan editor profesional untuk pemrograman VRML (Virtual Reality Modelling Language). Kemampuan utamanya meliputi kemampuan editorial yang powerful dan dukungan visual untuk scene tree dan resources operation. VrmlPad adalah alat yang powerful dan fleksibel dari ParallelGraphics yang memungkinkan kita untuk mendesain dan mengembangkan konten VRML.

\subsection{3ds Max}

3ds Max adalah program komputer berbasis 3D untuk modeling, rendering, dan animasi yang sangat populer dan banyak digunakan di berbagai bidang. Dengan variasi objek, material dan pencahayaan yang dimilikinya, 3ds Max biasa digunakan dalam aplikasi arsitektur, interior, mekanik, ataupun industri film dan game. Fitur-fitur yang di sediakan di dalamnya memungkinkan user menuangkan semua ide kreatif ke dalam komputer. Dapat dikatakan, bahwa kemampuan 3ds Max dibatasi oleh imaginasi user, yaitu seberapa jauh user mampu mengelola dan mengoptimalkan semua fitur yang ada dalam 3ds Max (Soma 2007).

\subsection{Metode Pengembangan Waterfall}

Model air terjun (waterfall) sering juga disebut model sekuensial linier atau alur hidup klasik (clasic life cycle). Model air terjun menyediakan pendekatan alur hidup perangkat lunak secara sekuensial atau terurut dimulai dari analisis, desain, pengodean, pengujian, dan tahap pendukung (support) (A.S. \& Shalahuddin 2013).

\subsection{Pemodelan Proses Data Flow Diagram (DFD)}

Data Flow Diagram (DFD) atau dalam bahasa Indonesia menjadi Diagram Alir Data (DAD) adalah representasi grafik yang menggambarkan aliran informasi dan transformasi informasi yang diaplikasikan sebagai data yang mengalir dari masukan (input) dan keluaran (output).

DFD dapat digunakan untuk merepresentasikan sebuah system atau perangkat lunak pada beberapa level abstraksi. DFD dapat dibagi menjadi beberapa level yang lebih detail untuk merepresentasikan aliran informasi atau fungsi yang lebih detail. DFD menyediakan mekanisme untuk pemodelan fungsional ataupun pemodelan aliran informasi. Oleh karena itu, DFD lebih sesuai digunakan untuk memodelkan fungsi-fungsi perangkat lunak yang akan diimplementasikan menggunakan pemrograman terstruktur karena pemrograman terstruktur membagibagi bagiannya dengan fungsi-fungsi dan prosedur (A.S. \& Shalahuddin 2013). 


\section{PERANCANGAN SISTEM}

3.1 Analisis Kebutuhan

3.1.1 Kebutuhan Fungsional

a. Adanya pembagian user menjadi tiga kelompok, yaitu : Admin, Operator dan Visitor

b. Adanya fasilitas login untuk admin dan operator untuk dapat mengakses database sistem sesuai hak akses masing-masing.

c. Adanya fasilitas admin untuk menambah, mengubah dan menghapus data mobil.

d. Adanya fasilitas admin untuk menambah, mengubah dan menghapus data objek virtual 3D mobil.

e. Adanya fasilitas admin untuk menambah, mengubah dan menghapus data artikel.

f. Adanya fasilitas admin untuk menambah, mengubah dan menghapus data profil.

g. Adanya fasilitas admin untuk menambah, mengubah dan menghapus data operator.

h. Adanya fasilitas admin untuk menghapus data komentar.

i. Adanya fasilitas operator untuk menambah, mengubah dan menghapus data mobil.

j. Adanya fasilitas operator untuk menambah, mengubah dan menghapus data objek virtual 3D mobil.

k. Adanya fasilitas operator untuk menambah, mengubah dan menghapus data artikel.

1. Adanya fasilitas operator untuk menghapus data komentar.

m. Adanya fasilitas logout untuk admin dan operator.

n. Adanya fasilitas visitor untuk melihat bentuk dan spesifikasi mobil.

o. Adanya fasilitas informasi penggunaan dan penginstallan plug-in Cortona3D Viewer pada browser untuk visitor.

p. Adanya fasilitas visitor untuk melihat objek virtual 3D mobil pada website.

q. Adanya fasilitas visitor untuk berinteraksi dengan objek virtual 3D mobil.

r. Adanya fasilitas visitor untuk memberikan komentar pada artikel website.

1.1.2 Kebutuhan Non Fungsional

a. Operasional

Sistem dapat dijalankan menggunakan berbagai browser yang mendukung Javascript dan Cortona3D Viewer.

b. Keamanan

Adanya penggunaan password dan pemilihan level dalam form login untuk membedakan pengguna dan hak akses masing-masing.

c. Antarmuka / Interface

Kebutuhan terhadap antarmuka yang diinginkan bersifat user friendly, artinya pengguna dapat menggunakan perangkat lunak yang dibuat dengan mudah dan senyaman mungkin.

\subsection{Analisis Sistem}

\subsubsection{Data Flow Diagram}

DFD dapat dibagi menjadi beberapa level yang lebih detail untuk merepresentasikan aliran informasi atau fungsi yang lebih detail. Berikut ini DFD level 0 yang menggambarkan dasar sistem aplikasi teknologi VRML untuk media promosi mobil berbasis web. Terdapat tiga entitas dan satu proses yang dapat dilihat pada gambar 1 dibawah ini.

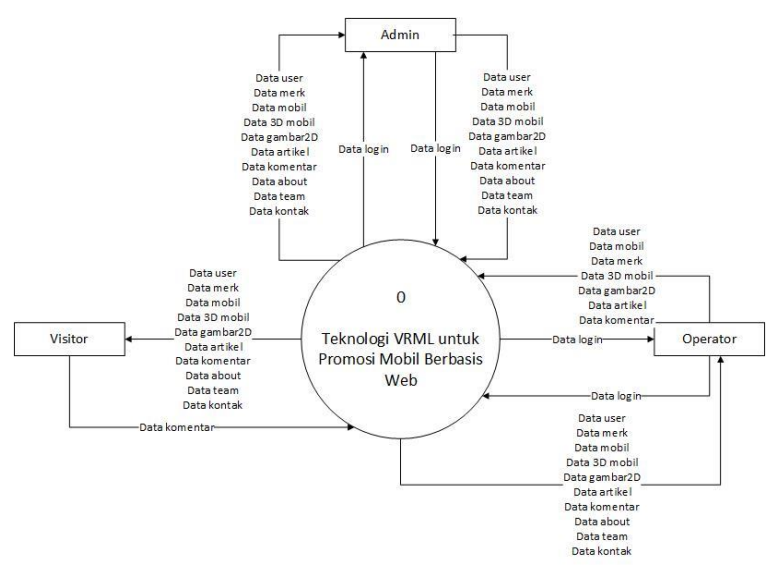

Gambar 1. DFD level 0

DFD Level 0 diatas didekomposisi menjadi DFD level 1 seperti yang digambarkan pada gambar 2 berikut ini.

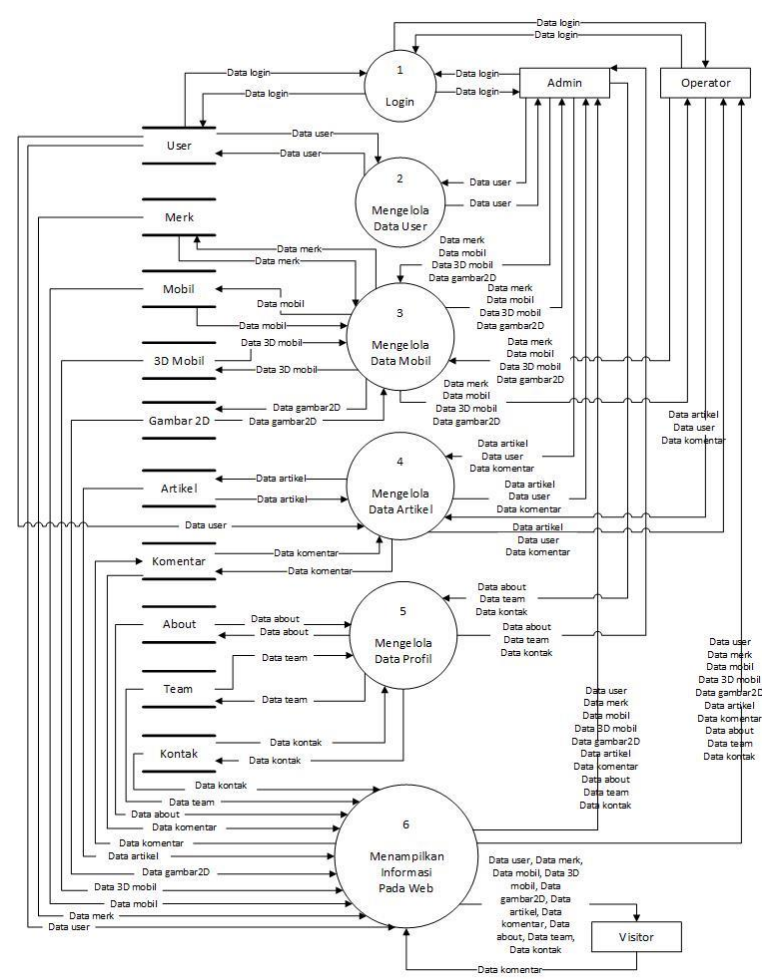

Gambar 2. DFD level 1

Terdapat enam proses dalam sistem aplikasi teknologi VRML untuk media promosi mobil berbasis web, yaitu : 


\section{a. Login}

Merupakan proses validasi untuk pengguna agar dapat mengakses sistem sesuai dengan hak akses masing-masing. Terdapat dua pengguna dalam sistem, yaitu admin dan operator, yang harus melalui proses login untuk dapat mengakses sistem sesuai otoritasnya masing-masing.

b. Mengelola Data User

Proses ini merupakan proses untuk melakukan pengelolaan terhadap data pengguna yang dapat masuk ke dalam sistem. Pada proses ini yang berhak melakukan pengelolaan adalah admin.

c. Mengelola Data Mobil

Proses ini merupakan proses untuk melakukan pengelolaan terhadap data mobil. Proses mengelola data mobil ini nantinya masih akan dibagi lagi menjadi subproses mengelola data merk, mengelola data spesifikasi mobil dan mengelola data 3D mobil. Pengguna yang dapat melakukan pengolahan data mobil ini adalah admin dan operator.

d. Mengelola Data Profil

Proses ini merupakan proses untuk melakukan pengelolaan terhadap data profil tentang pemilik atau pengelola $w e b$. Proses mengelola data profil ini dibagi menjadi subproses mengelola data about, mengelola data team, dan mengelola data kontak. Pengguna yang dapat melakukan pengolahan data profil ini adalah admin.

e. Menampilkan Informasi pada $\mathrm{Web}$

Proses ini merupakan proses untuk menampilkan data-data yang telah dikelola oleh admin maupun operator pada website, sehingga semua pengguna dapat melihatnya. Pada proses ini visitor dapat memberikan komentar terhadap artikel yang ditampilkan.

DFD level 1 ini kemudian didekomposisi lagi menjadi proses yang lebih detil.

\subsection{Perancangan Basis Data}

\subsubsection{ERD (Entity Relationship Diagram)}

Tahapan ERD diawali dengan mengidentifikasi dan menetapkan seluruh himpunan entitas yang terlibat. Berikut pada tabel 1 entitas yang terlibat dalam sistem aplikasi teknologi VRML untuk media promosi mobil berbasis web, disertai dengan jenis entitas dan keterangan.

Tabel 1 Daftar Entitas yang terlibat

\begin{tabular}{|c|c|c|l|}
\hline No. & $\begin{array}{c}\text { Nama } \\
\text { Entitas }\end{array}$ & $\begin{array}{c}\text { Jenis } \\
\text { Entitas }\end{array}$ & \multicolumn{1}{|c|}{ Keterangan } \\
\hline 1 & User & $\begin{array}{c}\text { Entitas } \\
\text { kuat }\end{array}$ & $\begin{array}{l}\text { Entitas yang berisi data } \\
\text { user, yaitu admin dan } \\
\text { operator }\end{array}$ \\
\hline 2 & Merk & $\begin{array}{c}\text { Entitas } \\
\text { kuat }\end{array}$ & $\begin{array}{l}\text { Entitas yang berisi data } \\
\text { merk mobil }\end{array}$ \\
\hline 3 & Mobil & $\begin{array}{c}\text { Entitas } \\
\text { lemah }\end{array}$ & $\begin{array}{l}\text { Entitas yang berisi data } \\
\text { spesifikasi mobil yang } \\
\text { dipromosikan }\end{array}$ \\
\hline 4 & Objek3d & $\begin{array}{c}\text { Entitas } \\
\text { lemah }\end{array}$ & $\begin{array}{l}\text { Entitas yang berisi data } \\
\text { objek 3d dari mobil }\end{array}$ \\
\hline
\end{tabular}

\begin{tabular}{|c|c|c|l|}
\hline 5 & Gambar2d & $\begin{array}{c}\text { Entitas } \\
\text { lemah }\end{array}$ & $\begin{array}{l}\text { Entitas yang berisi data } \\
\text { gambar 2d dari mobil }\end{array}$ \\
\hline 6 & Artikel & $\begin{array}{c}\text { Entitas } \\
\text { kuat }\end{array}$ & $\begin{array}{l}\text { Entitas yang berisi data } \\
\text { artikel yang akan } \\
\text { ditampilkan pada } \\
\text { website }\end{array}$ \\
\hline 7 & Komentar & $\begin{array}{l}\text { Entitas } \\
\text { lemah }\end{array}$ & $\begin{array}{l}\text { Entitas yang berisi data } \\
\text { komentar dari artikel } \\
\text { yang ditampilkan }\end{array}$ \\
\hline 8 & About & $\begin{array}{c}\text { Entitas } \\
\text { kuat }\end{array}$ & $\begin{array}{l}\text { Entitas yang berisi data } \\
\text { profil seputar pemilik } \\
\text { atau pengelola website }\end{array}$ \\
\hline 9 & Team & $\begin{array}{c}\text { Entitas } \\
\text { kuat }\end{array}$ & $\begin{array}{l}\text { Entitas yang berisi data } \\
\text { profil seputar pemilik } \\
\text { atau pengelola website }\end{array}$ \\
\hline 10 & Kontak & $\begin{array}{c}\text { Entitas } \\
\text { kuat }\end{array}$ & $\begin{array}{l}\text { Entitas yang berisi } \\
\text { kontak dari pemilik atau } \\
\text { pengelola website }\end{array}$ \\
\hline
\end{tabular}

Setelah diketahui entitas apa saja yang terlibat pada sistem, selanjutnya adalah menentukan atribut apa saja terdapat pada masing-masing entitas tersebut. Relasi antar Entitas kemudian ditentukan setelah entitas dan atribut terlah terdefenisi. Berikut ini beberapa relasi antar entitas yang terdapat pada sistem.

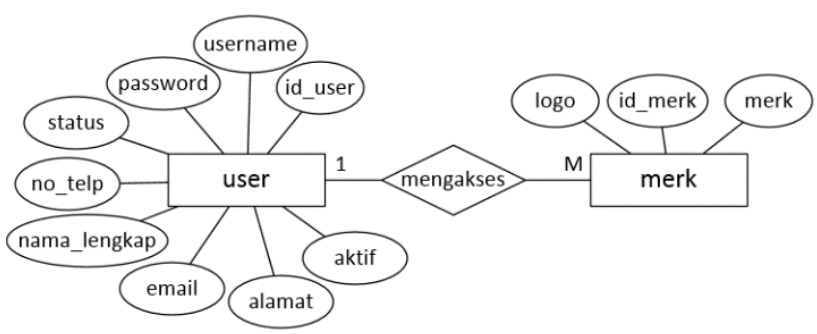

Gambar 3. Relasi entitas user dan merk

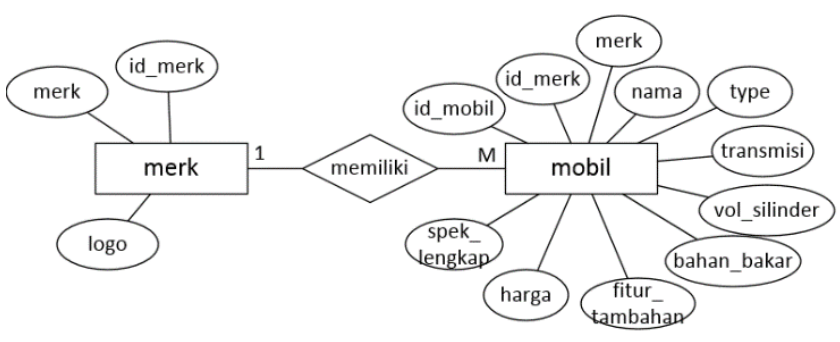

Gambar 4. Relasi entitas merk dan mobil

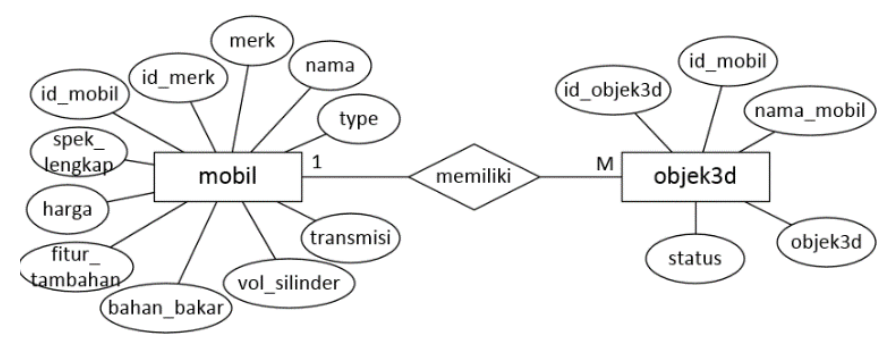

Gambar 5. Relasi entitas mobil dan objek3d

Setelah relasi tersebut dibuat, kemudian ditransformasikan kedalam bentuk tabel. 
3.4 Pembuatan Objek 3D Mobil

Objek 3D mobil merupakan visualisasi untuk menirukan mobil asli di dunia nyata ke dalam dunia maya. Proses pembuatan objek 3D mobil memerlukan beberapa langkah seperti pada gambar 6 .

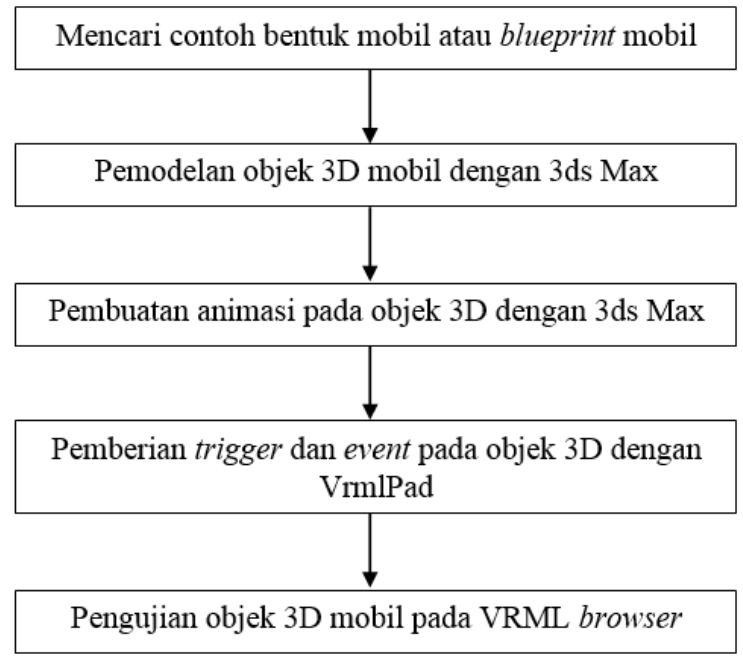

Gambar 6. Langkah pembuatan objek 3D mobil

\section{IMPLEMENTASI DAN PENGUJIAN SISTEM}

\subsection{Implementasi Sistem}

\subsubsection{Implementasi Basis Data}

Pada aplikasi teknologi VRML untuk media promosi mobil berbasis website, penyimpanan data yang digunakan adalah basis data MySQL. Basis data yang digunakan oleh sistem ini memiliki nama "web3d_mobil". Pada basis data "web3d_mobil" terdapat 10 tabel yang membangun jalannya proses pada sistem ini. Tabel yang dibuat tersebut disesuaikan dengan perancangan basis data sistem yang sudah dijelaskan sebelumnya.

\begin{tabular}{|c|c|c|c|c|c|c|c|c|c|}
\hline Table & \multicolumn{6}{|c|}{ Action } & Records 1 & Type & Collation \\
\hline tabel_about & 渻 & 通 & 閳 & sit & iii & $x$ & 4 & MyISAM & utf8_general_ci \\
\hline tabel_artikel & 霜 & 医 & 间 & 承 & 而 & $x$ & 4 & MyISAM & utf__general_ci \\
\hline tabel_gambar2d & 霜 & 楼 & 曾 & jat & i⿱一⿱㇒⿵冂⿰丨丨刂⿺ & $x$ & 5 & MyISAM & utf8_general_ci \\
\hline tabel_komentar & 霜 & 屆 & 温 & jiti & iili & $x$ & 1 & MyISAM & utf8_general_ci \\
\hline tabel_kontak & 霜 & 递 & 国 & 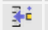 & IIII & $x$ & 6 & MyISAM & utf8_general_ci \\
\hline tabel_merk & 霜 & 里 & 国 & zisi & i⿱一⿱㇒⿵冂⿰丨丨寸 & $x$ & 4 & MyISAM & utf8_general_ci \\
\hline tabel_mobil & 霜 & 丰 & 国 & $\bar{j} \mathbf{i}$ & 洏 & $x$ & 4 & MyISAM & utf8_general_ci \\
\hline tabel_objek3d & 霜 & 速 & 国 & zisi & iiï & $x$ & 5 & MyISAM & utf__general_ci \\
\hline tabel_team & 雨 & 乐 & 温 & 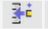 & 而 & $x$ & 3 & MyISAM & utf8_general_ci \\
\hline tabel_user & 霜 & 递 & 娄 & 通i & iiil & $x$ & 5 & MyISAM & utf8_general_ci \\
\hline 10 table(s) & & & su & um & & & 41 & MyISAM & utf8_general \\
\hline
\end{tabular}

\subsubsection{Implementasi Antarmuka}

Implementasi antarmuka meliputi implementasi halaman website dan tampilan objek 3D mobil. Website diimplementasikan menggunakan bahasa pemrograman PHP dan HTML, serta untuk mempercantik tampilan menggunakan CSS, Javascript dan JQuery.

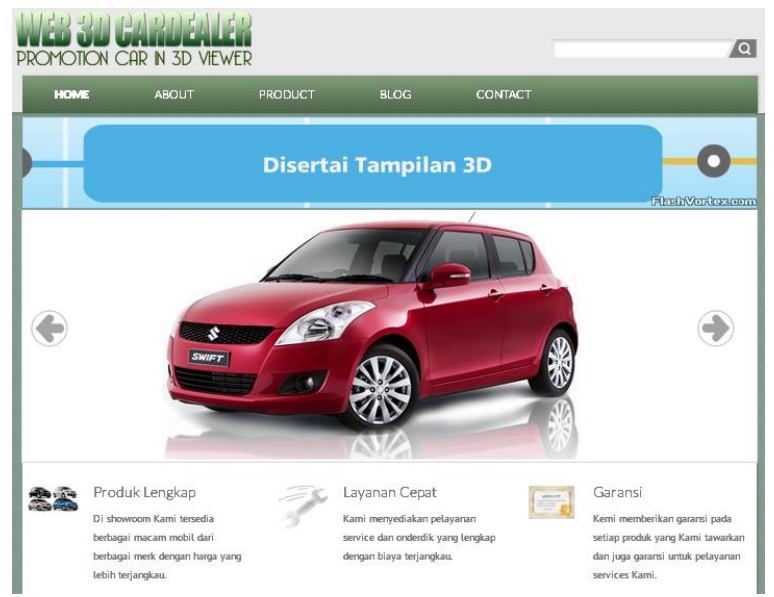

Gambar 8. Tampilan halaman home pada website

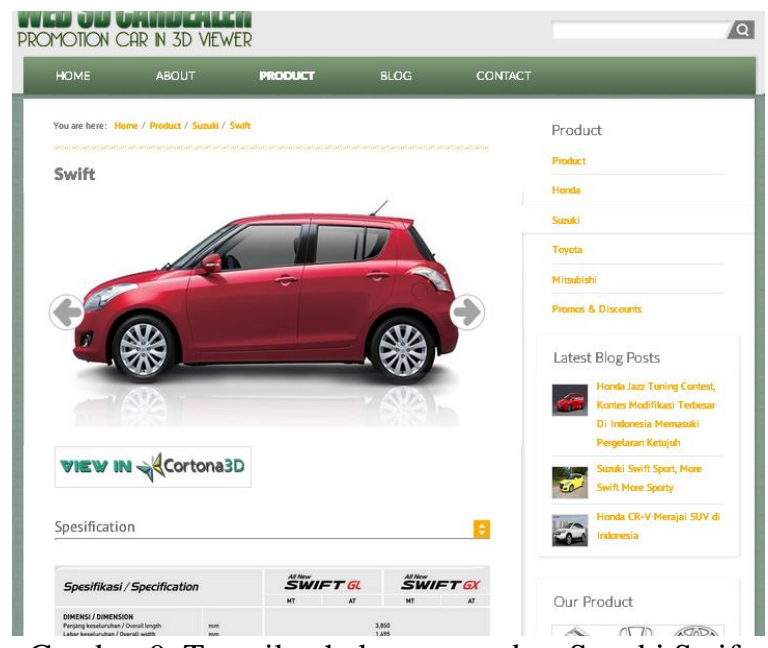

Gambar 9. Tampilan halaman product Suzuki Swift

File objek 3D yang akan ditampilkan pada halaman web harus berekstensi .wrl dan browser yang digunakan untuk menampilkannya harus sudah terinstall Cortona3D Viewer. Selanjutnya untuk memanggil file objek 3D dan menampilkannya diperlukan penambahan script berikut pada dokumen HTML-nya.

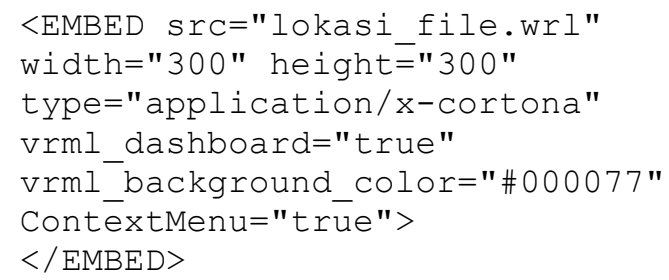

Penulisan untuk Src atau lokasi file 3D haruslah tepat sesuai lokasi file 3D tersebut disimpan. Vrml_dashboard digunakan untuk menampilkan menu navigasi Cortona3D. Untuk ukuran width, height, background disesuaikan dengan kebutuhan. Beikut ini merupakan tampilan objek 3D pada halaman website. 


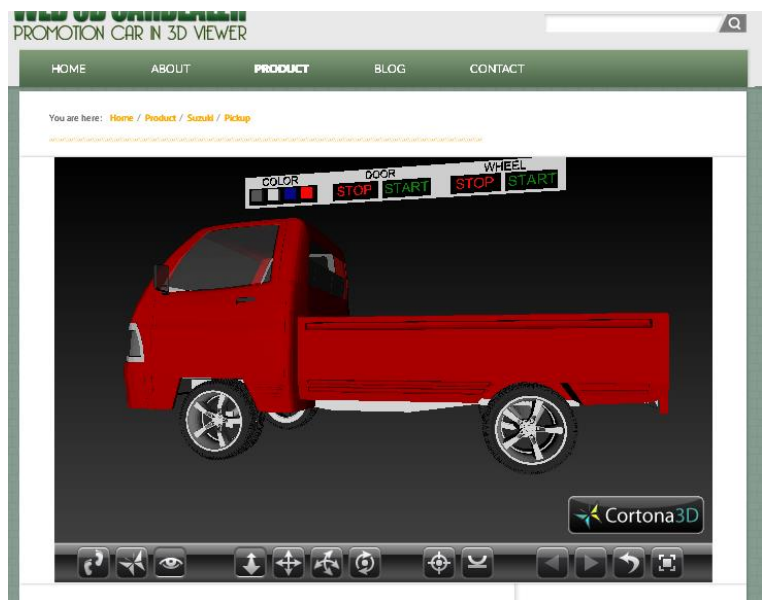

Gambar 10. Tampilan file 3D pada website melalui Cortona3D Viewer

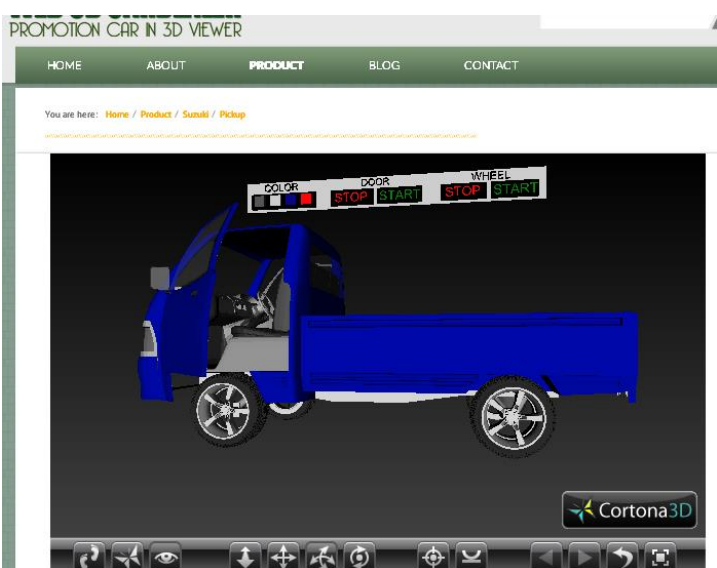

Gambar 11. Animasi buka pintu dan ganti warna

Data yang akan ditampilkan pada halaman website disimpan dalam basis data. Untuk mempermudah pengelolaan data tersebut maka dibuat halaman untuk user admin dan operator. Berikut ini contoh halaman untuk pengelolaan data.

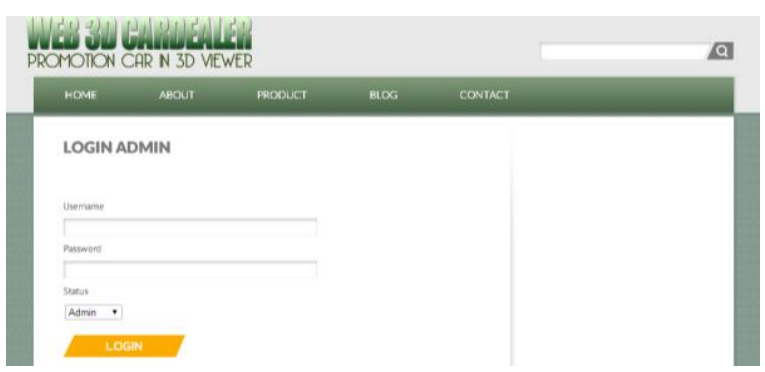

Gambar 12. Halaman login admin dan operator

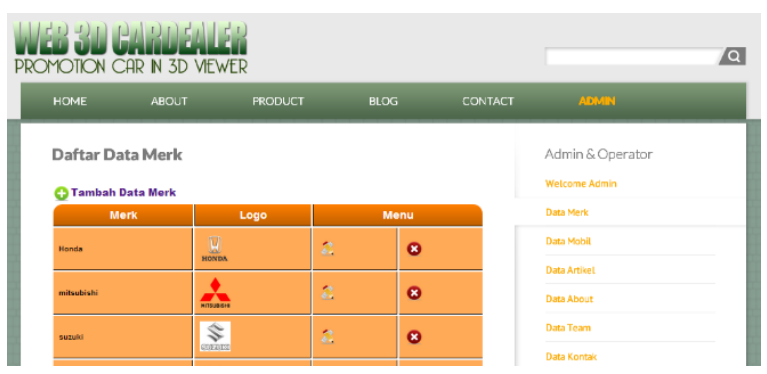

Gambar 13. Tampilan halaman data merk

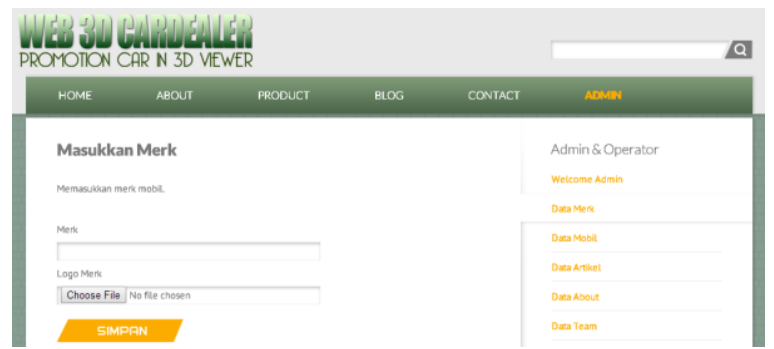

Gambar 14. Tampilan menu tambah data merk

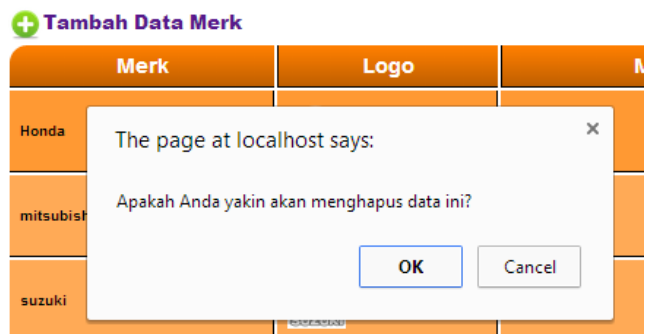

Gambar 15. Tampilan peringatan hapus data merk

\subsubsection{Pengujian Aplikasi}

Pengujian perangkat lunak diperlukan untuk menghindari terjadinya banyak error sebelum perangkat lunak diberikan kepada pelanggan atau selama perangkat lunak masih terus dikembangkan.

Pengujian perangkat lunak pada aplikasi teknologi VRML untuk media promosi mobil berbasis web ini menggunakan metode Black box. Pengujian Black box berfokus pada persyaratan fungsional perangkat lunak.

Tabel 2. Pengujian login

\begin{tabular}{|c|c|c|c|}
\hline $\begin{array}{c}\text { Nama } \\
\text { pengujian }\end{array}$ & $\begin{array}{c}\text { Bentuk } \\
\text { pengujian }\end{array}$ & $\begin{array}{l}\text { Hasil yang } \\
\text { diharapkan }\end{array}$ & $\begin{array}{c}\text { Hasil } \\
\text { pengujian }\end{array}$ \\
\hline $\begin{array}{l}\text { Login } \\
\text { admin }\end{array}$ & $\begin{array}{l}\text { Memasukkan } \\
\text { kombinasi } \\
\text { username, } \\
\text { password dan } \\
\text { status "admin", } \\
\text { dengan benar }\end{array}$ & $\begin{array}{l}\text { Dapat } \\
\text { mengakses } \\
\text { halaman admin }\end{array}$ & Berhasil \\
\hline $\begin{array}{l}\text { Login } \\
\text { operator }\end{array}$ & $\begin{array}{l}\text { Memasukkan } \\
\text { kombinasi } \\
\text { username, } \\
\text { password dan } \\
\text { status } \\
\text { "operator" } \\
\text { dengan benar }\end{array}$ & $\begin{array}{l}\text { Dapat } \\
\text { mengakses } \\
\text { halaman } \\
\text { operator }\end{array}$ & Berhasil \\
\hline Login salah & $\begin{array}{l}\text { Memasukan } \\
\text { kombinasi } \\
\text { username, } \\
\text { password dan } \\
\text { status yang } \\
\text { salah } \\
\end{array}$ & $\begin{array}{l}\text { Kembali ke } \\
\text { halaman login } \\
\text { dan tidak dapat } \\
\text { mengakses } \\
\text { halaman admin } \\
\text { atau operator }\end{array}$ & Berhasil \\
\hline
\end{tabular}

Tabel 3. Pengujian pengolahan data mobil

\begin{tabular}{|l|l|l|l|}
\hline \multicolumn{1}{|c|}{$\begin{array}{c}\text { Nama } \\
\text { pengujian }\end{array}$} & $\begin{array}{c}\text { Bentuk } \\
\text { pengujian }\end{array}$ & \multicolumn{1}{c|}{$\begin{array}{c}\text { Hasil yang } \\
\text { diharapkan }\end{array}$} & $\begin{array}{c}\text { Hasil } \\
\text { pengujian }\end{array}$ \\
\hline $\begin{array}{l}\text { Melihat } \\
\text { daftar } \\
\text { mobil }\end{array}$ & $\begin{array}{l}\text { Mengklik } \\
\text { menu data } \\
\text { mobil }\end{array}$ & $\begin{array}{l}\text { Menampilkan } \\
\text { tabel daftar mobil } \\
\text { yang tersedia pada } \\
\text { database }\end{array}$ & Berhasil \\
\hline $\begin{array}{l}\text { Menambah } \\
\text { data mobil }\end{array}$ & $\begin{array}{l}\text { Mengklik } \\
\text { menu } \\
\text { tambah data } \\
\text { mobil }\end{array}$ & $\begin{array}{l}\text { Muncul tampilan } \\
\text { untuk mengisi data } \\
\text { mobil }\end{array}$ & Berhasil \\
\hline
\end{tabular}




\begin{tabular}{|c|c|c|c|}
\hline & $\begin{array}{l}\text { Mengisi } \\
\text { semua field } \\
\text { data mobil } \\
\text { dan klik } \\
\text { simpan }\end{array}$ & $\begin{array}{l}\text { 1. Muncul } \\
\text { peringatan } \\
\text { pengecekan } \\
\text { ulang data } \\
\text { 2. Data merk yang } \\
\text { dimasukkan } \\
\text { tersimpan di } \\
\text { database } \\
\text { 3. Data } \\
\text { ditampilkan di } \\
\text { tabel daftar } \\
\text { mobil } \\
\end{array}$ & Berhasil \\
\hline & $\begin{array}{l}\text { Tidak } \\
\text { mengisi } \\
\text { field data } \\
\text { mobil dan } \\
\text { klik simpan }\end{array}$ & $\begin{array}{l}\text { 1. Muncul } \\
\text { peringatan } \\
\text { pengecekan } \\
\text { ulang data } \\
\text { 2. Kembali pada } \\
\text { tampilan untuk } \\
\text { mengisi data } \\
\text { mobil }\end{array}$ & Berhasil \\
\hline \multirow{3}{*}{$\begin{array}{l}\text { Mengubah } \\
\text { data mobil }\end{array}$} & $\begin{array}{l}\text { Mengklik } \\
\text { menu edit } \\
\text { data mobil }\end{array}$ & $\begin{array}{l}\text { Muncul tampilan } \\
\text { untuk mengubah } \\
\text { data mobil }\end{array}$ & Berhasil \\
\hline & $\begin{array}{l}\text { Mengubah } \\
\text { beberapa } \\
\text { detail data } \\
\text { mobil dan } \\
\text { klik simpan }\end{array}$ & $\begin{array}{l}\text { 1. Muncul } \\
\text { peringatan } \\
\text { pengecekan } \\
\text { ulang data } \\
\text { 2. Data yang } \\
\text { mengalami } \\
\text { perubahan } \\
\text { sukses } \\
\text { tersimpan di } \\
\text { database } \\
\text { 3. Data } \\
\text { ditampilkan di } \\
\text { tabel daftar } \\
\text { mobil } \\
\end{array}$ & Berhasil \\
\hline & $\begin{array}{l}\text { Tidak } \\
\text { mengubah } \\
\text { detail data } \\
\text { mobil dan } \\
\text { klik simpan }\end{array}$ & $\begin{array}{l}\text { 1. Muncul } \\
\text { peringatan } \\
\text { pengecekan } \\
\text { ulang data } \\
\text { 2. Data } \\
\text { ditampilkan di } \\
\text { tabel daftar } \\
\text { mobil }\end{array}$ & Berhasil \\
\hline $\begin{array}{l}\text { Menghapus } \\
\text { data mobil }\end{array}$ & $\begin{array}{l}\text { Mengklik } \\
\text { menu hapus } \\
\text { pada data } \\
\text { mobil }\end{array}$ & $\begin{array}{l}\text { 1. Muncul pesan } \\
\text { peringatan } \\
\text { penghapusan } \\
\text { data mobil } \\
\text { 2. Data merk } \\
\text { berhasil dihapus } \\
\text { dari database } \\
\text { 3. Data yang } \\
\text { dihapus tidak } \\
\text { ditampilkan di } \\
\text { daftar mobil }\end{array}$ & Berhasil \\
\hline
\end{tabular}

Tabel 4. Pengujian pengolahan data objek3D

\begin{tabular}{|l|l|l|l|}
\hline \multicolumn{1}{|c|}{$\begin{array}{c}\text { Nama } \\
\text { pengujian }\end{array}$} & \multicolumn{1}{c|}{$\begin{array}{c}\text { Bentuk } \\
\text { pengujian }\end{array}$} & \multicolumn{1}{|c|}{$\begin{array}{c}\text { Hasil yang } \\
\text { diharapkan }\end{array}$} & $\begin{array}{c}\text { Hasil } \\
\text { pengujian }\end{array}$ \\
\hline $\begin{array}{l}\text { Melihat } \\
\text { daftar } \\
\text { objek 3D }\end{array}$ & $\begin{array}{l}\text { Mengklik } \\
\text { menu } \\
\text { "lihat" data } \\
\text { selanjutnya } \\
\text { pada daftar } \\
\text { data mobil }\end{array}$ & $\begin{array}{l}\text { Menampilkan } \\
\text { daftar objek 3D } \\
\text { mobil yang } \\
\text { tersedia pada } \\
\text { database }\end{array}$ & Berhasil \\
\hline $\begin{array}{l}\text { Menambah } \\
\text { data objek }\end{array}$ & $\begin{array}{l}\text { Mengklik } \\
\text { menu } \\
\text { tambah data } \\
\text { objek 3D }\end{array}$ & $\begin{array}{l}\text { Muncul tampilan } \\
\text { untuk mengisi data } \\
\text { objek 3D }\end{array}$ & Berhasil \\
\hline
\end{tabular}

\begin{tabular}{|c|c|c|c|}
\hline & $\begin{array}{l}\text { Mengisi } \\
\text { semua field } \\
\text { data objek } \\
\text { 3D dan klik } \\
\text { simpan }\end{array}$ & $\begin{array}{l}\text { 1. Muncul } \\
\text { peringatan } \\
\text { pengecekan } \\
\text { ulang data } \\
\text { 2. Data objek 3D } \\
\text { yang } \\
\text { dimasukkan } \\
\text { tersimpan di } \\
\text { database } \\
\text { 3. File objek 3D } \\
\text { tersimpan } \\
\text { dilokasi yang } \\
\text { sudah } \\
\text { ditentukan } \\
\text { 4. Data } \\
\text { ditampilkan di } \\
\text { daftar objek 3D }\end{array}$ & Berhasil \\
\hline & $\begin{array}{l}\text { Tidak } \\
\text { mengisi } \\
\text { field data } \\
\text { objek 3D } \\
\text { dan klik } \\
\text { simpan }\end{array}$ & $\begin{array}{l}\text { 1. Muncul } \\
\text { peringatan } \\
\text { pengecekan } \\
\text { ulang data } \\
\text { 2. Kembali pada } \\
\text { tampilan } \\
\text { mengisi data } \\
\text { objek 3D }\end{array}$ & Berhasil \\
\hline \multirow{3}{*}{$\begin{array}{l}\text { Mengubah } \\
\text { data objek } \\
\text { 3D }\end{array}$} & $\begin{array}{l}\text { Mengklik } \\
\text { menu edit } \\
\text { data objek } \\
\text { 3D }\end{array}$ & $\begin{array}{l}\text { Muncul tampilan } \\
\text { untuk mengubah } \\
\text { data objek 3D }\end{array}$ & Berhasil \\
\hline & $\begin{array}{l}\text { Mengubah } \\
\text { data objek } \\
\text { 3D dan klik } \\
\text { simpan }\end{array}$ & $\begin{array}{l}\text { 1. Muncul } \\
\text { peringatan } \\
\text { pengecekan } \\
\text { ulang data } \\
\text { 2. Data yang } \\
\text { mengalami } \\
\text { perubahan } \\
\text { sukses } \\
\text { tersimpan di } \\
\text { database } \\
\text { 3. File objek 3D } \\
\text { lama terhapus } \\
\text { dan file 3D yang } \\
\text { baru tersimpan } \\
\text { dilokasi yang } \\
\text { sudah } \\
\text { ditentukan } \\
\text { 4. Data } \\
\text { ditampilkan di } \\
\text { daftar objek 3D }\end{array}$ & Berhasil \\
\hline & $\begin{array}{l}\text { Tidak } \\
\text { mengubah } \\
\text { data objek } \\
\text { 3D dan klik } \\
\text { simpan }\end{array}$ & $\begin{array}{l}\text { 1. Muncul } \\
\text { peringatan } \\
\text { pengecekan } \\
\text { ulang data } \\
\text { 2. Data } \\
\text { ditampilkan di } \\
\text { daftar objek 3D }\end{array}$ & Berhasil \\
\hline $\begin{array}{l}\text { Mengaktifk } \\
\text { an objek } \\
\text { 3D }\end{array}$ & $\begin{array}{l}\text { Mengklik } \\
\text { icon lampu } \\
\text { dari data } \\
\text { objek 3D }\end{array}$ & $\begin{array}{l}\text { Objek 3D yang } \\
\text { diaktifkan akan } \\
\text { ditampilkan pada } \\
\text { halaman product } \\
\text { dari website } \\
\text { melalui Cortona3D } \\
\text { Viewer }\end{array}$ & Berhasil \\
\hline
\end{tabular}




\begin{tabular}{|c|c|c|c|}
\hline $\begin{array}{l}\text { Menghapus } \\
\text { data objek } \\
\text { 3D }\end{array}$ & $\begin{array}{l}\text { Mengklik } \\
\text { menu hapus } \\
\text { pada data } \\
\text { objek 3D }\end{array}$ & $\begin{array}{l}\text { 1. Muncul pesan } \\
\text { peringatan } \\
\text { penghapusan } \\
\text { data } \\
\text { 2. Data objek 3D } \\
\text { berhasil dihapus } \\
\text { dari database } \\
\text { 3. File objek 3D } \\
\text { terhapus dari } \\
\text { lokasi } \\
\text { penyimpanan } \\
\text { 4. Data yang } \\
\text { dihapus tidak } \\
\text { ditampilkan di } \\
\text { daftar objek 3D }\end{array}$ & Berhasil \\
\hline
\end{tabular}

Tabel 5. Pengujian penampil objek 3D mobil

\begin{tabular}{|c|c|c|c|}
\hline $\begin{array}{c}\text { Nama } \\
\text { pengujian }\end{array}$ & $\begin{array}{c}\text { Bentuk } \\
\text { pengujian }\end{array}$ & $\begin{array}{l}\text { Hasil yang } \\
\text { diharapkan }\end{array}$ & $\begin{array}{c}\text { Hasil } \\
\text { pengujian }\end{array}$ \\
\hline $\begin{array}{l}\text { Penampil } \\
\text { objek 3D } \\
\text { mobil } \\
\text { melalui } \\
\text { Cortona3D }\end{array}$ & $\begin{array}{l}\text { Memilih } \\
\text { menu View } \\
\text { in } \\
\text { Cortona3D } \\
\text { pada } \\
\text { halaman } \\
\text { product }\end{array}$ & $\begin{array}{l}\text { 1. Dapat } \\
\text { menampilkan } \\
\text { objek 3D mobil } \\
\text { yang tersimpan } \\
\text { pada database } \\
\text { 2. Menampilkan } \\
\text { menu-menu } \\
\text { navigasi } \\
\text { Cortona3D } \\
\end{array}$ & Berhasil \\
\hline $\begin{array}{l}\text { Fungsi } \\
\text { menu-menu } \\
\text { navigasi } \\
\text { Cortona3D }\end{array}$ & $\begin{array}{l}\text { Memilih } \\
\text { menu } \\
\text { navigasi } \\
\text { yang } \\
\text { ditampilkan } \\
\text { Cortona3D } \\
\end{array}$ & $\begin{array}{l}\text { Tiap-tiap menu } \\
\text { navigasi dapat } \\
\text { berjalan dengan } \\
\text { benar sesuai } \\
\text { pedoman di } \\
\text { Cortona3D }\end{array}$ & Berhasil \\
\hline $\begin{array}{l}\text { Pergantian } \\
\text { warna } \\
\text { objek 3D } \\
\text { mobil }\end{array}$ & $\begin{array}{l}\text { Mengklik } \\
\text { warna yang } \\
\text { diinginkan } \\
\text { di tampilan } \\
\text { 3D mobil }\end{array}$ & $\begin{array}{l}\text { Objek 3D mobil } \\
\text { dapat berubah } \\
\text { warna sesuai } \\
\text { warna yang dipilih } \\
\text { oleh user }\end{array}$ & Berhasil \\
\hline $\begin{array}{l}\text { Animasi } \\
\text { buka pintu } \\
\text { pada objek } \\
\text { 3D mobil }\end{array}$ & $\begin{array}{l}\text { Mengklik } \\
\text { start dan } \\
\text { stop pada } \\
\text { menu door } \\
\text { di tampilan } \\
\text { 3D mobil }\end{array}$ & $\begin{array}{l}\text { 1. Pintu mobil } \\
\text { pada objek 3D } \\
\text { mobil dapat } \\
\text { terbuka dalam } \\
\text { jangka waktu } \\
\text { tertentu lalu } \\
\text { akan menutup } \\
\text { kembali } \\
\text { 2. Animasi akan } \\
\text { terhenti ketika } \\
\text { tombol stop } \\
\text { ditekan } \\
\end{array}$ & Berhasil \\
\hline $\begin{array}{l}\text { Animasi } \\
\text { roda } \\
\text { berputar } \\
\text { pada objek } \\
\text { 3D mobil }\end{array}$ & $\begin{array}{l}\text { Mengklik } \\
\text { start dan } \\
\text { stop pada } \\
\text { menu wheel } \\
\text { di tampilan } \\
\text { 3D mobil }\end{array}$ & $\begin{array}{l}\text { 1. Roda mobil } \\
\text { pada objek 3D } \\
\text { dapat berputar } \\
\text { dalam jangka } \\
\text { waktu tertentu } \\
\text { 2. Animasi akan } \\
\text { terhenti ketika } \\
\text { tombol stop } \\
\text { ditekan }\end{array}$ & Berhasil \\
\hline
\end{tabular}

Tabel 6. Pengujian browser menampilkan VRML

\begin{tabular}{|l|l|l|c|}
\hline \multicolumn{1}{|c|}{$\begin{array}{c}\text { Nama } \\
\text { pengujian }\end{array}$} & $\begin{array}{c}\text { Google } \\
\text { Chrome }\end{array}$ & Mozilla Firefox & IE \\
\hline $\begin{array}{l}\text { Menampilkan } \\
\text { semua halaman } \\
\text { website }\end{array}$ & Berhasil & $\begin{array}{l}\text { Berhasil, namun } \\
\text { ada tampilan } \\
\text { yang kurang } \\
\text { sesuai }\end{array}$ & Berhasil \\
\hline $\begin{array}{l}\text { Menginstall } \\
\text { plug-in } \\
\text { Cortona3D } \\
\text { Viewer }\end{array}$ & Berhasil & Berhasil & Berhasil \\
\hline
\end{tabular}

\begin{tabular}{|l|l|l|l|}
\hline $\begin{array}{l}\text { Menampilkan } \\
\text { objek 3D mobil } \\
\text { melalui } \\
\text { Cortona3D }\end{array}$ & Berhasil & Berhasil & Berhasil \\
\hline $\begin{array}{l}\text { Menjalankan } \\
\text { fungsi menu } \\
\text { navigasi } \\
\text { Cortona3D }\end{array}$ & Berhasil & Berhasil & Berhasil \\
\hline
\end{tabular}

\section{KESIMPULAN DAN SARAN}

\subsection{Kesimpulan}

Berdasarkan hasil pengujian dan analisis aplikasi teknologi VRML untuk media promosi mobil berbasis web, maka dapat disimpulkan beberapa hal sebagai berikut.

1. Teknologi VRML dapat diimplementasikan dalam pembuatan objek 3D mobil guna mendukung aplikasi interaktif berbasis web untuk media promosi mobil.

2. Penggunaan tampilan 3D mobil yang interaktif memungkinkan pengguna untuk dapat berinteraksi dengan objek 3D mobil, seperti memutar objek 3D mobil untuk melihat mobil dari segala sisi, mengganti warna mobil, membuka pintu mobil, dll.

3. Pengguna yang dapat mengakses aplikasi teknologi VRML untuk media promosi mobil berbasis web dikelompokkan menjadi tiga sesuai dengan hak aksesnya masing-masing, yaitu admin, operator dan visitor.

4. Berdasarkan hasil pengujian menggunakan metode Black Box, menu-menu utama yang tersedia pada aplikasi teknologi VRML berbasis web ini telah berjalan dengan benar sesuai fungsinya.

\subsection{Saran}

Berdasarkan hasil pengujian dan analisis aplikasi teknologi VRML untuk media promosi mobil berbasis web, dapat diberikan beberapa saran sebagai berikut.

1. Pengembang aplikasi VRML dapat melakukan pengembangan terhadap pembuatan objek 3D mobil agar lebih mendetail namun dengan ukuran file yang kecil sehingga lebih cepat ketika diakses.

2. Pengembang disarankan dapat mengembangkan aplikasi VRML sebagai media promosi ini agar dapat dijalankan pada perangkat bergerak (mobile device) seperti smartphone.

\section{DAFTAR PUSTAKA}

[1] A.S., R. \& Shalahuddin, M., 2013. Rekayasa Perangkat Lunak Terstruktur dan Berorientasi Objek, Bandung: Informatika.

[2] Adi, A.P. \& Sanjaya, R., 2012. Web Makin Dahsyat dengan JQuery, Semarang: Kompas Gramedia

[3] Anwar, B., 1999a. Belajar Sendiri Bahasa Pemrograman VRML 1.0, Jakarta: PT Elex Media Komputindo. 
[4] Anwar, B., 1999b. Belajar Sendiri Bahasa Permrograman VRML 97, Jakarta: PT Elex Media Komputindo.

[5] Cahyadi, A.N. \& Hananto, M.W., 2011. Pemasaran Perumahan Menggunakan Teknologi Virtual Reality Modelling Language ( VRML ) ( Studi Kasus PT S etia G raha P radipta ). , 1(2), pp.165-173.

[6] Coltekin, A., Heikkinen, J. \& Ronnholm, P., 2003. Studying Geometry, Color, and Texture in VRML, Helsinki: Institute of Photogrammetry and Remote Sensing, Helsinki University of Technology.

[7] Fadillah, M.H., 2011. Implementasi VRML pada Media Pembelajaran Geometri untuk Sekolah Dasar dengan Menggunakan Metode Pembentukan Objek EKstrusi. Institut Pertanian Bogor.

[8] Hirin, A.. \& Virgi, 2011. Cepat Mahir Pemrograman Web demgan PHP dan MySQL, Jakarta: Prestasi Pustakarya.

[9] Kadir, A., 2009a. From Zero to a Pro Membuat Aplikasi Web dengan PHP dan Database MySQL, Yogyakarta: Andi Offset.

[10] Kadir, A., 2009b. Mastering AJAX dan PHP, Yogyakarta: Andi Offset.

[11] Kurniadi, A., 1999. Membuat Dunia 3D dengan VRML, Jakarta: PT Elex Media Komputindo.

[12] Kurniawan, R., 2008. Perancangan Sistem Informasi Seminar dan Tugas Akhir Mahasiswa Jurusan Teknik Elektro Undip. Universitas Diponegoro.

[13] Kusumaningrum, K., 2013. Sistem Informasi Kerja Praktek dan Tugas Akhir Program Studi Sistem Komputer. Universitas Diponegoro.
[14] Madcoms, 2004. Aplikasi Program PHP dan MySQL, Yogyakarta: Andi Offset.

[15] Madcoms, 2011. Dreamweaver CS5 - PHP - MySQL untuk Pemula, Andi Offset.

[16] Nugroho, B., 2008. Latihan Membuat Aplikasi Web PHP dan MySQL dengan Dreamweaver, Yogyakarta: Gaya Media.

[17] Paoluzzi, A., 2003. Geometric Programming for Computer Aided Design, Chicester, UK: John Wiley \& Sons.

[18] Raharjo, B., Heryanto, I. \& Enjang, R., 2012. Modul Pemrograman Web HTML, PHP, dan MySQL Revisi., Bandung: Modula.

[19] Soma, H.A., 2007. Dasar-Dasar Modeling dan Animasi Dengan 3D Studio Max, Jakarta: PT Elex Media Komputindo.

[20] Wahyono, T., 2009. Practice Guide PHP On Windows, Jakarta: PT Elex Media Komputindo.

[21] http://www.cortona3d.com/cortona3dviewer diakses Senin, 2 April 2013, pukul 21.00 WIB.

[22] http://www.parallelgraphics.com/products/vrmlpa d/features - diakses Kamis, 14 November 2013 pukul 20.58 WIB 